Situs Jurnal : http://ejournal.stiepancasetia.ac.id/index.php/jieb

Jilid 6 Nomor 1 Maret 2020

Hal 99 - 114

\title{
ANALISIS KUALITAS PELAYANAN LEMBAGA PELATIHAN KURSUS KOMPUTER UNTUK MENINGKATKAN KEPUASAN SISWA PADA PONDOK PESANTREN DARUL HIJRAH PUTRA CINDAI ALUS MARTAPURA
}

\author{
Jaya Bahwiyanti* dan Rama Andri Syawalli \\ Sekolah Tinggi IImu Ekonomi Pancasetia, Jl. Ahmad Yani. Telp. (0511) 3256560 \\ Fax. (0511) 3256557 Banjarmasin - 70248
}

Abstrak: Tujuan dari penelitian ini adalah untuk mengetahui tingkat kepuasan pada siswa SMP kelas 1 pada Pondok Pesantren Darul Hijrah Putra Martapura yang dilihat dri faktor kualitas pelayananya yang menyangkut bukti fisik / tangible, kehandalan / reliability, daya tanggap / Responsevenees, Jaminan / Assurance dan Empati / Empathy.Metode penelitian yang digunakan adalah jenis Deskriptif kuantitatif dengan membahas sebuah penelitian dengan angka-angka. Angka yang diperoleh dari berupa kuesioner yang dibagikan terhadap 100 siswa dan nanti akan dihitung indeks persentase guna mengetahui tingkat kepuasan dari variabel kualitas pelayanan. Hasil penelitian menunjukan bahwa semua variabel kualitas pelayanan LPK-AL-Hijrah mendapatkan nilai Cukup Puas oleh siswa yang memperoleh hasil Indeks Persentase dengan jarak interprestasi 20\% dari 5 kategori pilihan adalah $48,31 \%$.

Kata Kunci : Kualitas Pelayanan, Kepuasan siswa, Lembaga Kursus Komputer.

\section{Latar Belakang Masalah}

Lembaga pendidikan merupakan suatu lembaga yang bertujuan mengembangkan potensi anak-anak agar mampu menjalankan kehidupan sebagai manusia, kegiatan untuk mengembangkan potensi itu harus dilakukan secara berencana, terarah dan sistematik guna mencapai tujuan tertentu. Untuk mencapai tujuan tersebut diperlukan suatu organisasi lembaga pendidikan dapat ditentukan berdasarkan kriteria-kriteria tertentu.

Dalam rangka pemenuhan kebutuhan akan teknologi komputer maka banyak bermunculan lembaga-lembaga kursus salah satunya lembaga kursus komputer Pondok Pesantren Darul Hijrah Putra Cindai Alus martapura. Dengan adanya lembaga kursus komputer tersebut diharapkan siswa mampunyai pengetahuan dan kemampuan teknologi komputer yang sangat dibutuhkan pada era globalisasi modern sekarang ini.

Kepuasan merupakan tingkat perasaan yang sesuai dengan harapan, tetapi pada kenyataan tidak demikian yang terjadi pada LPK Pondok Pesantren Putra Darul Hijrah Cindai Alus Martapura dimana kualitas pelayanan yang diberikan tidak sesuai dengan harapan sehingga mengakibatkan siswa merasa tidak puas. 


\section{Kajian Literatur}

Menurut Kotler (2011:13) Manajemen pemasaran adalah analisis, perencanaan, Implementasi dan pengendalian program yang dirancang untuk menciptakan, membangun dan mempertahankan pertukaran yang menguntungkan dengan target pembeli untuk tujuan mencapai objektif organisasi. Ada tiga faktor utama yang menyebabkan terjadinya perubahan strategi dalam pemasaran yaitu:

1. Daur hidup produk

2. Posisi persaingan perusahaan dipasar

3. Situasi ekonomi

Menurut Tjiptono (2014:230), kualitas pelayanan jasa adalah tingkatan yang diharapkan dan pengendalian atas tingkat keunggulan tersebut untuk memenuhi keinginan pelanggan.

Difinisi lain dikemukakan oleh Arikunto (2013:221), dimana kualitas pelayanan sebagai layanan yang diterima konsumen telah sesuai dengan harapan konsumen akan kualitas.

Kualitas pelayanan menurut Stemvelt (2014) adalah suatu persepsi tentang revolusi kualitas secara menyeluruh yang terpikirkan dan menjadi suatu gagasan yang harus dirumuskan (formulasi) agar penerapannya (implementasi) dapat diuji kembali (evaluasi), untuk menjadi suatu proses yang dinamis, berlangsung, terus menerus dalam memenuhi kepuasan pelanggan. Indikator kualitas pelayanan menurut Parasuraman, Zeithaml, dan Berry yang dikutip oleh Fandy Tjiptono (2012:198) terdapat 5 dimensi kualitas layanan beserta definisi operasionalnya :

1. Bukti Langsung (Tangibles) adalah bentuk aktualisasi nyata secara fisik dapat terlihat atau digunakan oleh pegawai sesuai dengan penggunaan dan pemanfaatannya yang dapat dirasakan membantu pelayanan yang diterima oleh orang yang menginginkan pelayanan, sehingga puas atas pelayanan yang dirasakan, indikator bukti langsung dalam penelitian ini yaitu :

a) Fasilitas yang cukup memadai seperti adanya kipas angin diruangan.

b) Kebersihan ruangan

c) Peralatan dan kualitasnya seperti komputer.

2. Kehandalan (Reliability) adalah setiap pegawai memiliki kemampuan yang handal, mengetahui mengenai seluk beluk prosedur kerja, mekanisme kerja, memperbaiki berbagai kekurangan atau penyimpangan yang tidak sesuai dengan prosedur kerja dan mampu menunjukkan, mengarahkan dan memberikan arahan yang benar kepada setiap bentuk pelayanan yang belum dimengerti oleh masyarakat sehingga memberi dampak positif atas pelayanan tersebut. Indikator dari kehandalan (reliability) yaitu

a) Pelayanan dari para karyawan sangat memuaskan.

b) Berbagai pilihan hadiah diberikan sesuai dengan hak pelanggan yang menggunakan.

c) Seluruh karyawan sopan dan rapi dalam penampilan

3. Daya Tanggap (responsiveness) yaitu keinginan para staf dan karyawan untuk membantu para pelanggan dan memberikan pelayanan dengan tanggap. Sehingga dimensi kualitas daya tanggap ini di dalam sebuah perusahaan haru benar-benar diwujudkan secara baik agar konsumen merasa dihargai atas 
tanggapan atau respon dari perusahaan atas segala keinginan dari konsumen. Indikator daya tanggap dalam penelitian ini yaitu :

a) Tanggap terhadap keluhan pelanggan

b) Kesediaan karyawan membantu pelanggan

c) Kecepatan karyawan dalam menyelesaikan masalah

4. Jaminan (assurance) adalah kemauan untuk menetapkan kerugian-kerugian kecil yang sudah pasti sebagai pengganti/substitusi kerugian-kerugian besar yang belum terjadi. Indikator jaminan dalam penelitian ini yaitu :

a) Adanya garansi jika pelayanan yang diberikan kurang memadai

b) Tersedia teknisi jika seandainya terjadinya sesuatukerusakan dalam hal ini komputer dan fasilitas lainnya

c) Tersedianya jaminan buku pedoman komputer gratis dan semua pasti mendapatkannya

5. Empati (Empathy) adalah perhatian secara individual yang diberikan perusahaan kepada pelanggan seperti kemudahan dalam menghubungi perusahaan, kemampuan karyawan untuk berkomunikasi dengan pelanggan, dan kebutuhan pelanggannya. Indikator empati dalam penelitian ini adalah :

a) Karyawan bertanggung jawab dalam tugasnya

b) Karyawan yang siap membantu dan melayani pelanggan dengan

Penelitian ini memiliki penelitian-penelitian terdahulu sebagai pedoman.

Beberapa penelitian terdahulu yang menunjang penelitian ini meliputi :

1. Amelia Mira tahun 2012 dengan judul "Analisis Pengaruh Kualitas Pelayanan Terhadap Kepuasan Siswa Dalam Mengikuti Kursus Di Lembaga Bimbingan Belajar IPIEMS Cabang Banyumanik Semarang". Hasil analisis dapat disimpulkan bahwa variabel bukti fisik/ tangible, keandalan/ reliability, daya tanggap/ responsiveness , jaminan/ assurance, dan empati/ empathy semuanya berpengaruh positif dan signifikan terhadap kepuasan siswa dalam mengikuti kursus di Lembaga Bimbingan Belajar IPIEMS Cabang Banyumanik Semarang.

2. Fatmah tahun 2015 dengan judul "Analisis kualitas pelayanan jasa terhadap kepuasan konsumen pada siswa Bimbingan Belajar dan Konsultasi Belajar Al Qolam Bandar Lampun". Penelitian ini dapat disimpulkan ada pengaruh kualitas pelayanan jasa terhadap kepuasan konsumen pada siswa Bimbingan dan Konsultasi belajar Al Qolam Bandar Lampung baik secara simultan maupun secara parsial.

3. Esy Nurjanah tahun 2010 yang berjudul "Analisis Kualitas Pelayanan Terhadap Kepuasan Konsumen Lembaga Pendidikan Komputer Borobudur Metro". Penelitian ini dengan hasil pelayanan yang diberikan belum bisa memenuhi harapan konsumen, karena hanya sekitar 54,15\% dari keseluruhan 5 dimensi kualitas pelayanan yang diberikan tidak sesuai dengan harapan konsumen.

\section{Metode Penelitian}

Dalam melakukan penelitian ada dua jenis data yang digunakan dalam penelitian ini adalah data kualitatif dan kuantitatif.

1. Data Kualitatif dalam penelitian ini berupa pernyataan responden dan pertanyaan yang diberikan dalam bentuk wawancara, observasi dan kuesioner. 
2. Data Kuantitatif dalam penelitian ini berupa analisa data yang diperoleh berdasarkan hasil kuesioner.

Sumber data dalam penelitian ini adalah data primer dan data sekunder

1. Data primer adalah data yang dikumpulkan oleh penulis secara langsung dari sumber yang menjadi objek penelitinya. Data yang bersumber dari Kuesioner, wawancara, pengamatan suatu peristiwa, orang dan objek, yakni Siswa SMP Kelas 1 (A,B,C,D,E,F,G) pada Lembaga Pelatihan Kursus Komputer terhadap Pondok Pesantren Darul Hijrah Putra Martapura yang mengikuti Pelatihan Kursus Komputer dengan jumlah 218 siswa.

2. Data sekunder adalah data yang diperoleh berasal dari dokumen-dokumen perusahaan itu sendiri. Beberapa sumber sekunder antara lain informasi yang dipublikasikan atau tidak dipublikasikan dari dalam atau luar perusahaan, data yang tersedia dari penelitian terdahulu.

Definisi Operasional Variabel

Menurut Parasuraman, Zeithaml, dan Berry yang dikutip oleh Fandy Tjiptono

(2012:198) mengemukakan bahwa dalam mengevaluasi jasa yang bersifat intangible, konsumen umumnya menggunakan atribut :

a. Bukti langsung (tangibles), meliputi fasilitas fisik, perlengkapan, pegawai dan sarana komunikasi. Bukti langsung memiliki beberapa indikator yaitu :

- Fasilitas yang cukup memadai seperti adanya kipas angin dirungan

- Kebersihan ruangan

- Peralatan dan kualitasnya seperti komputer

b. Keandalan (reliability), yakni kemampuan memberikan pelayanan yang dijanjikan dengan segera, akurat dan memuaskan. Indikatornya :

- Pelayanan dari karyawan yang sangat memuaskan.

- Berbagai pilihan hadiah atau imbalan yang diberikan sesuai hak pelanggan yang menggunakan.

- Selurih karyawan sopan dan rapi dalam penampilan.

c. Daya tanggap (responsibility), yaitu keinginan para staff dan karyawan untuk membantu para konsumen dan memberikan pelayanan dengan tanggap. Indikatornya :

- Tanggap terhadap keluhan pelanggan.

- Kesediaan karyawan membantu pelanggan.

- Kecepatan karyawan membantu pelanggan.

d. Jaminan (assurance), mencakup pengetahuan, kemampuan, kesopanan, dan sifat dapat dipercaya yang dimiliki para staff, bebas dari bahaya, resiko atau keragu-raguan. Indikatornya :

- Adanya garansi jika pelayanan yang diberikan kurang memadai.

- Tersedia teknisi jika seandainya terjadi sesuatu kerusakan dalam hal ini komputer dan fasilitas lainnya.

- Tersedianya jaminan buku pedoman komputer gratis dan semua dipastikan mendapatkannya.

e. Empati (empathy), meliputi kemudahan dalam melakukan hubungan, komunikasi yang baik, perhatian pribadi, dan memahami kebutuhan para konsumen. Indikatornya :

- Karyawan bertanggung jawab dalam tugasnya 
- Karyawan yang siap membantu dan melayani pelanggan dengan sepenuh hati.

Teknik analisa data yang digunakan dalam penelitian ini menggunakan Teknik Skala Likert dari hasil penilaian 100 responden, yaitu :

1. Tahap awal.

- Responden yang menjawab sangat suka (skor 5)

- Responden yang menjawab suka (skor 4)

- Responden yang menjawab netral (skor 3)

- Responden yang menjawab tidak suka (skor 2)

- Responden yang menjawab sangat tidak suka (skor 1)

Rumus: $\mathrm{T}$ x $\mathrm{Pn}$

$\mathrm{T}=$ Total jumlah responden yang memilih

$\mathrm{Pn}=$ Pilihan angka skor Likert

Interpretasi Skor Perhitungan agar mendapatkan hasil interpretasi, terlebih dahulu harus diketahui skor tertinggi $(X)$ dan skor terendah $(Y)$ untuk item penilaian dengan rumus sebagai berikut:

$Y=$ skor tertinggi likert $x$ jumlah responden

$\mathrm{X}=$ skor terendah likert $\mathrm{x}$ jumlah responden

Rumus Index \% = Total Skor / Y x 100

2. Pra Penyelesaian

Sebelum menyelesaikannya kita juga harus mengetahui interval (rentang jarak) dan interpretasi persen agar mengetahui penilaian dengan metode mencari Interval skor persen (I).

Rumus Interval

I = 100 / Jumlah Skor (Likert)

Maka $=100 / 5=20$

Hasil $(I)=20 \quad$ (Ini adalah intervalnya jarak dari terendah $0 \%$ hingga tertinggi $100 \%)$

Berikut kriteria interpretasi skornya berdasarkan interval:

a. Angka 0\% -19,99\% = Sangat (tidak setuju/buruk/kurang sekali)

b. Angka $20 \%-39,99 \%=$ Tidak setuju / Kurang baik)

c. Angka $40 \%-59,99 \%=$ Cukup $/$ Netral

d. Angka $60 \%-79,99 \%=($ Setuju/Baik/puas)

e. Angka $80 \%-100 \%$ = Sangat (setuju/Baik/puas)

Penyelesaian Akhir

$=$ Total skor $/ \mathrm{Y} \times 100$

$=247 / 500 \times 100$

$=49.4 \%$, berada dalam kategori "Cukup/Netral"

\section{Hasil Penelitian}

Berdasarkan kuesioner yang telah disebarkan kepada 100 responden diperoleh jawaban yang digunakan untuk mengetahui apakah kepuasan siswa 
dipengaruhi oleh kualitas pelayanan yang meliputi bukti langsung, kehandalan, daya tanggap, jaminan dan empaty serta untuk mengetahui seberapa besar pengaruhnya. Untuk memudahkan dalam membaca dan memahami hasil penelitian, penulis membuat tahapan-tahapan sebagai berikut :

1. Uji Validitas dilakukan untuk mengetahui tingkat kevalidan indikator yang digunakan sebagai alat ukur variabel. Pengujian validitas menggunakan korelasi bivariat yang dilakukan dengan menggunakan alat bantu komputer pada program IBM SPSS Statistics 25 for windows untuk menghitung korelasi antara skor masing-masing butir pertanyaan dengan total skor variabel, dengan kententuan jika nilai $r$-tabel $<$ r-hitung berarti valid dan sebaliknya, jika nilai $r$ tabel > r-hitung berati tidak valid. r-tabel yang dipakai sebagai nilai minimal pengukuran dengan menggunakan r-tabel menurut Sugiyono (2010: 455) dengan nilai 0,196 . Berikut ini hasil uji validitas masing-masing indikator :

\section{Tabel 1. Hasil Uji Validitas}

\begin{tabular}{|c|c|c|c|c|}
\hline \multicolumn{2}{|c|}{ Variabel } & $r$ - hitung & r-tabel & Keterangan \\
\hline \multicolumn{2}{|c|}{ Bukti langsung } & & & \\
\hline \multirow{4}{*}{$\mathrm{X} 1$} & Indikator X1.1 & 0,333 & 0,196 & Valid \\
\hline & Indikator X1.2 & 0,421 & 0,196 & Valid \\
\hline & Indikator X1.3 & 0,506 & 0,196 & Valid \\
\hline & Indikator X1.4 & 0,416 & 0,196 & Valid \\
\hline \multicolumn{2}{|c|}{ Kehandalan } & & & \\
\hline \multirow{3}{*}{$\mathrm{x} 2$} & Indikator X2.1 & 0,454 & 0,196 & Valid \\
\hline & Indikator X2.2 & 0,561 & 0,196 & Valid \\
\hline & Indikator X2.3 & 0,630 & 0,196 & Valid \\
\hline \multicolumn{2}{|c|}{ Daya Tanggap } & & & \\
\hline \multirow{4}{*}{$\mathrm{X} 3$} & Indikator X3.1 & 0,532 & 0,196 & Valid \\
\hline & Indikator X3.2 & 0,480 & 0,196 & Valid \\
\hline & Indikator X3.3 & 0,503 & 0,196 & Valid \\
\hline & Indikator X3.4 & 0,497 & 0,196 & Valid \\
\hline \multicolumn{2}{|c|}{ Jaminan } & & & \\
\hline \multirow{4}{*}{$\mathrm{X} 4$} & Indikator X4.1 & 0,530 & 0,196 & Valid \\
\hline & Indikator X4.2 & 0,594 & 0,196 & Valid \\
\hline & Indikator X4.3 & 0,470 & 0,196 & Valid \\
\hline & Indikator X4.4 & 0,443 & 0,196 & Valid \\
\hline & npaty & & & \\
\hline \multirow{5}{*}{ X5 } & Indikator X5.1 & 0,424 & 0,196 & Valid \\
\hline & Indikator X5.2 & 0,456 & 0,196 & Valid \\
\hline & Indikator X5.3 & 0,613 & 0,196 & Valid \\
\hline & Indikator X5.4 & 0,430 & 0,196 & Valid \\
\hline & Indikator X5.5 & 0,463 & 0,196 & Valid \\
\hline
\end{tabular}


variabel bukti fisik, keandalan, daya tanggap, jaminan dan empaty dinyatakan Valid. karena hasil korelasi antara jawaban responden pada tiap item pertanyaan /indikator dengan skor total di dapat hasil yang signifikan.

2. Uji Reliabilitas merupakan pengujian sejauh mana hasil suatu pengukuran dapat dipercaya. Ketentuan pengukuran pada setiap variabel jika nilai Alpha > Tingkat Koefisien maka dinyatakan Reliabel. Nilai minimal pengukuran yang digunakan adalah menurut Sugiyono (2010: 455) dengan ketentuan nilai Tingkat Koefisien 0,196 . Dengan menggunakan alat bantu komputer pada program IBM SPSS Statistics 25 for windows maka dapat diketahui nilai alpha sebagai berikut :

Tabel 2: Hasil Uji Reliabel

\begin{tabular}{|c|l|c|c|c|}
\hline No & \multicolumn{1}{|c|}{ Variabel } & Alpha & $\begin{array}{c}\text { Tingkat } \\
\text { Koefisien }\end{array}$ & Keterangan \\
\hline 1 & Bukti langsung (X1) & 0,622 & 0,196 & Reliabel \\
\hline 2 & Kehandalan (X2) & 0,599 & 0,196 & Reliabel \\
\hline 3 & Daya tanggap (X3) & 0,596 & 0,196 & Reliabel \\
\hline 4 & Jaminan (X4) & 0,661 & 0,196 & Reliabel \\
\hline 5 & Empaty (X5) & 0,700 & 0,196 & Reliabel \\
\hline
\end{tabular}

Sumber : data diolah peneliti

Dengan berdasarkan hasil uji diketahui bahwa semua pertanyaan adalah reliabel. Hal ini karena nilai alpha ( $\alpha$ ) yang melebihi dari nilai Tingkat Harapan / Koefisien yaitu 0,196 . Maka setiap kuesioner yang telah dibuat bisa dipercaya serta dapat dipakai untuk mendukung penelitian ini.

Rekapitulasi Tanggapan Siswa

Indeks tingkat kepuasan terhadap kualitas pelayanan lembaga kursus komputer pada pondok pesantren darul hijrah putra martapura. Hasil kuesioner yang telah dibagikan kepada 100 orang responden yaitu siswa LPK Al-Hijrah SMP kelas 1 yang di tabulasi dan diinterpretasikan dalam bentuk distribusi frekuensi dan diklasifikasi kategori penilaian adalah :

1. Tabel 3: Frekuensi Bukti Langsung 


\begin{tabular}{|c|c|c|c|c|c|c|c|c|c|c|c|c|c|}
\hline \multirow{3}{*}{ Bukti Langsung } & \multicolumn{10}{|c|}{ Tanggapan } & \multirow{3}{*}{ Total Skor } & \multirow{3}{*}{ Indeks \% } & \multirow{3}{*}{ Indikator } \\
\hline & \multicolumn{2}{|c|}{ SP } & \multicolumn{2}{|c|}{$\mathrm{P}$} & \multicolumn{2}{|c|}{$C P$} & \multicolumn{2}{|c|}{ TP } & \multicolumn{2}{|c|}{ STP } & & & \\
\hline & $\mathrm{F}$ & $\begin{array}{l}\text { skor } \\
\text { item }\end{array}$ & $\mathrm{F}$ & $\begin{array}{l}\text { skor } \\
\text { item }\end{array}$ & $\mathrm{F}$ & $\begin{array}{l}\text { skor } \\
\text { item }\end{array}$ & $\mathrm{F}$ & $\begin{array}{l}\text { skor } \\
\text { item }\end{array}$ & $F$ & $\begin{array}{l}\text { skor } \\
\text { item }\end{array}$ & & & \\
\hline $\begin{array}{l}\text { Kerapian dan } \\
\text { kebersihan berpakaian }\end{array}$ & 2 & 5 & 31 & 124 & 57 & 171 & 9 & 18 & 1 & 1 & 324 & 64,8 & PUAS \\
\hline $\begin{array}{l}\text { Kebersihan ruangan } \\
\text { kelas secara umum }\end{array}$ & 0 & 0 & 4 & 16 & 41 & 123 & 35 & 70 & 20 & 20 & 229 & 45,8 & $\begin{array}{l}\text { CUKUP } \\
\text { PUAS }\end{array}$ \\
\hline $\begin{array}{l}\text { Kenyamana an ruang } \\
\text { lingkup dan fasilitas } \\
\text { saat digunakan }\end{array}$ & 0 & 0 & 2 & 8 & 30 & 90 & 45 & 90 & 23 & 23 & 211 & 42,2 & $\begin{array}{l}\text { CUKUP } \\
\text { PUAS }\end{array}$ \\
\hline $\begin{array}{l}\text { Kualitas komputer } \\
\text { saat digunakan } \\
\text { sebagai mdia belajar }\end{array}$ & 1 & 5 & 18 & 72 & 62 & 186 & 16 & 32 & 3 & 3 & 298 & 59,6 & $\begin{array}{l}\text { CUKUP } \\
\text { PUAS }\end{array}$ \\
\hline
\end{tabular}

Sumber: data diolah peneliti

Berdasarkan hasil analisis menunjukan sebanyak 31 orang atau 64,8 \% menyatakan puas dengan pernyataan "Kerapian dan kebersihan berpakaian". Sebanyak 41 orang atau 45,8\% responden menyatakan cukup puas dengan pernyataan mengenai "Kebersihan ruangan kelas secara umum". Sebanyak 30 orang atau $42,2 \%$ responden menyatakan cukup puas dengan pernyataan mengenai "Kenyamanan ruang lingkup dan fasilitas saat digunakan". Dan sebanyak 62 orang atau $59,6 \%$ responden menyatakan cukup puas dengan pernyataan mengenai "Kualitas komputer saat digunakan sebagai media belajar"

2. Tabel 4: Frekuensi Kehandalan.

\begin{tabular}{|c|c|c|c|c|c|c|c|c|c|c|c|c|c|}
\hline \multirow{3}{*}{ Kehandalan } & \multicolumn{10}{|c|}{ Tanggapan } & \multirow{3}{*}{ Total Skor } & \multirow{3}{*}{ Indeks \% } & \multirow{3}{*}{ Indikator } \\
\hline & \multicolumn{2}{|c|}{ SP } & \multicolumn{2}{|c|}{$\mathrm{P}$} & \multicolumn{2}{|c|}{$\mathrm{CP}$} & \multicolumn{2}{|c|}{ TP } & \multicolumn{2}{|c|}{ STP } & & & \\
\hline & $F$ & $\begin{array}{l}\text { skor } \\
\text { item }\end{array}$ & $F$ & $\begin{array}{l}\text { skor } \\
\text { item }\end{array}$ & $F$ & $\begin{array}{l}\text { skor } \\
\text { item }\end{array}$ & $\mathrm{F}$ & $\begin{array}{l}\text { skor } \\
\text { item }\end{array}$ & $F$ & $\begin{array}{l}\text { skor } \\
\text { item }\end{array}$ & & & \\
\hline $\begin{array}{l}\text { Pemberian nilai } \\
\text { sesuai kriteria }\end{array}$ & 1 & 5 & 18 & 72 & 51 & 153 & 18 & 36 & 12 & 12 & 278 & 55,6 & $\begin{array}{l}\text { CUKUP } \\
\text { PUAS }\end{array}$ \\
\hline $\begin{array}{l}\text { Pemeberian } \\
\text { sertifikasi legalitas } \\
\text { pengajar }\end{array}$ & 1 & 5 & 3 & 12 & 26 & 78 & 48 & 96 & 22 & 22 & 213 & 42,6 & $\begin{array}{l}\text { CUKUP } \\
\text { PUAS }\end{array}$ \\
\hline $\begin{array}{l}\text { Kemudahan proses } \\
\text { penyampaian teori } \\
\text { dan arahan tutor }\end{array}$ & 1 & 5 & 1 & 4 & 31 & 93 & 49 & 98 & 18 & 18 & 218 & 43,6 & $\begin{array}{l}\text { CUKUP } \\
\text { PUAS }\end{array}$ \\
\hline
\end{tabular}

Sumber: data diolah peneliti

Berdasarkan hasil analisis menunjukan sebanyak 51 orang atau 55,6\% menyatakan cukup puas mengenai pernyataan "Pemberian nilai sesuai kriteria". Sebanyak 26 orang atau $42,6 \%$ menyatakan cukup puas mengenai pernyataan "Pemberian sertifikasi legalitas pengajar". Sebanyak 31 orang atau 43,6\% cukup puas mengenai pernyataan "Kemudahan proses penyampaian teori dan arahan tutor". 
3. Tabel 5: Frekuensi Daya Tanggap.

\begin{tabular}{|c|c|c|c|c|c|c|c|c|c|c|c|c|c|}
\hline \multirow{3}{*}{ Daya Tanggap } & \multicolumn{10}{|c|}{ Tanggapan } & \multirow{3}{*}{ Total Skol } & \multirow{3}{*}{ Indeks \% } & \multirow{3}{*}{ Indikator } \\
\hline & \multicolumn{2}{|c|}{ SP } & \multicolumn{2}{|c|}{$P$} & \multicolumn{2}{|c|}{$\mathrm{CP}$} & \multicolumn{2}{|c|}{ TP } & \multicolumn{2}{|c|}{ STP } & & & \\
\hline & $F$ & \begin{tabular}{|l|} 
skor \\
item
\end{tabular} & $F$ & $\begin{array}{l}\text { skor } \\
\text { item }\end{array}$ & $\mathrm{F}$ & \begin{tabular}{|l|} 
skor \\
item
\end{tabular} & $\mathrm{F}$ & \begin{tabular}{|l|} 
skor \\
item
\end{tabular} & $\mathrm{F}$ & \begin{tabular}{|l|} 
skor \\
item
\end{tabular} & & & \\
\hline $\begin{array}{l}\text { Kesigapan tutor dalam } \\
\text { memperbaiki jika } \\
\text { peralatan rusak }\end{array}$ & 0 & 0 & 2 & 8 & 37 & 111 & 51 & 102 & 10 & 10 & 231 & 46,2 & $\begin{array}{l}\text { CUKUP } \\
\text { PUAS }\end{array}$ \\
\hline $\begin{array}{l}\text { Kesigapan dan } \\
\text { tanggapan menangani } \\
\text { keluhan siswa }\end{array}$ & 0 & 0 & 1 & 4 & 28 & 84 & 54 & 108 & 17 & 17 & 213 & 42,6 & $\begin{array}{l}\text { CUKUP } \\
\text { PUAS }\end{array}$ \\
\hline $\begin{array}{l}\text { Kesigapan dalam } \\
\text { melayani administrasi } \\
\text { dan nilai siswa yang } \\
\text { bermasalah }\end{array}$ & 2 & 10 & 9 & 36 & 38 & 114 & 42 & 84 & 9 & 9 & 253 & 50,6 & $\begin{array}{l}\text { CUKUP } \\
\text { PUAS }\end{array}$ \\
\hline $\begin{array}{l}\text { Kesiapan tutor dalam } \\
\text { mengawali proses } \\
\text { belajar }\end{array}$ & 1 & 5 & 4 & 16 & 50 & 150 & 33 & 84 & 12 & 12 & 267 & 53,4 & $\begin{array}{l}\text { CUKUP } \\
\text { PUAS }\end{array}$ \\
\hline
\end{tabular}

Sumber: diolah peneliti

Berdasarkan hasil analisis menunjukan sebanyak 37 orang atau 46,2\% menyatakan cukup puas dengan pernyataan "Kesigapan tutor dalam memperbaiki jika peralatan rusak". Sebanyak 28 orang atau 42,6\% menyatakan cukup puas mengenai pernyataan "Kesigapan dan tanggapan menangani keluhan siswa". Sebanyak 38 orang atau $50,6 \%$ menyatakan cukup puas mengenai pernyataan "Kesigapan dalam melayani administrasi dan nilai siswa yang bermasalah". Sebanyak 50 orang atau $53,4 \%$ menyatakan cukup puas mengenai pernyataan "Kesiapan tutor dalam mengawali proses belajar".

4. Tabel 6: Frekuensi Jaminan. 


\begin{tabular}{|c|c|c|c|c|c|c|c|c|c|c|c|c|c|}
\hline \multirow[b]{3}{*}{ Jaminan } & \multicolumn{10}{|c|}{ Tangqapan } & \multirow[b]{3}{*}{ Total Skor } & \multirow[b]{3}{*}{ Indeks \% } & \multirow[b]{3}{*}{ Indikator } \\
\hline & \multicolumn{2}{|c|}{ SP } & \multicolumn{2}{|c|}{$\mathrm{P}$} & \multicolumn{2}{|c|}{$\mathrm{CP}$} & \multicolumn{2}{|c|}{ TP } & \multicolumn{2}{|c|}{ STP } & & & \\
\hline & $\mathrm{F}$ & $\begin{array}{l}\text { skor } \\
\text { item }\end{array}$ & $\mathrm{F}$ & $\begin{array}{l}\text { skor } \\
\text { item }\end{array}$ & $\mathrm{F}$ & $\begin{array}{l}\text { skor } \\
\text { item }\end{array}$ & $\mathrm{F}$ & $\begin{array}{l}\text { skor } \\
\text { item }\end{array}$ & $\mathrm{F}$ & $\begin{array}{l}\text { skor } \\
\text { item }\end{array}$ & & & \\
\hline $\begin{array}{l}\text { Keramahan tutor dalam } \\
\text { menyampaikan pelajaran }\end{array}$ & 0 & 0 & 1 & 4 & 17 & 51 & 56 & 66 & 26 & 26 & 147 & 29,4 & $\begin{array}{l}\text { TIDAK } \\
\text { PUAS }\end{array}$ \\
\hline $\begin{array}{l}\text { Kejujuran tutor dalam } \\
\text { mengajarkan yg harus } \\
\text { diajarkan }\end{array}$ & 2 & 10 & 3 & 12 & 31 & 93 & 48 & 112 & 16 & 16 & 243 & 48,6 & $\begin{array}{l}\text { CUKUP } \\
\text { PUAS }\end{array}$ \\
\hline $\begin{array}{l}\text { Keterampilan tutor dalam } \\
\text { menyampaikan materi } \\
\text { pelajaran }\end{array}$ & 0 & 0 & 3 & 12 & 13 & 39 & 33 & 66 & 51 & 51 & 168 & 33,6 & $\begin{array}{l}\text { TIDAK } \\
\text { PUAS }\end{array}$ \\
\hline $\begin{array}{l}\text { Keterampilan teknisi } \\
\text { dalam memperbaiki } \\
\text { gangguan teknis }\end{array}$ & 1 & 5 & 20 & 80 & 45 & 135 & 21 & 42 & 13 & 13 & 275 & 55 & $\begin{array}{l}\text { CUKUP } \\
\text { PUAS }\end{array}$ \\
\hline
\end{tabular}

Sumber: diolah peneliti

Berdasarkan hasil analisis menunjukan 56 orang atau 29,4\% menyatakan tidak puas mengenai penyataan "Keramahan tutor dalam menyampaikan pelajaran". Sebanyak 31 orang atau 48,6\% menyatakan cukup puas mengenai pernyataan "Kejujuran tutor dalam mengajarkan yang harus diajarkan". Sebanyak 33 orang atau $33,6 \%$ menyatakan tidak puas mengenai penyataan "Keterampilan tutor dalam menyampaikan materi pelajaran". Dan sebanyak 45 orang atau 55\% menyatakan cukup puas mengenai pernyataan "Keterampilan teknisi dalam memperbaiki gangguan teknis"

5. Tabel 7: Frekuensi Empaty.

\begin{tabular}{|c|c|c|c|c|c|c|c|c|c|c|c|c|c|}
\hline \multirow{3}{*}{ Empaty } & \multicolumn{10}{|c|}{ Tanggapan } & \multirow{3}{*}{ Total Skor } & \multirow{3}{*}{ Indeks \% } & \multirow{3}{*}{ Indikator } \\
\hline & \multicolumn{2}{|c|}{ SP } & \multicolumn{2}{|c|}{$\mathrm{P}$} & \multicolumn{2}{|c|}{$\mathrm{CP}$} & \multicolumn{2}{|c|}{ TP } & \multicolumn{2}{|c|}{ STP } & & & \\
\hline & $\mathrm{F}$ & \begin{tabular}{|l} 
skor \\
item
\end{tabular} & $\mathrm{F}$ & \begin{tabular}{|l} 
skor \\
item
\end{tabular} & $\mathrm{F}$ & $\begin{array}{l}\text { skor } \\
\text { item }\end{array}$ & $\mathrm{F}$ & $\begin{array}{l}\text { skor } \\
\text { item }\end{array}$ & $\mathrm{F}$ & $\begin{array}{l}\text { skor } \\
\text { item }\end{array}$ & & & \\
\hline $\begin{array}{l}\text { Sikap tutor dalam } \\
\text { menyampai kan salam } \\
\text { pada siswa }\end{array}$ & 2 & 10 & 15 & 60 & 52 & 156 & 29 & 58 & 2 & 2 & 286 & 57,2 & $\begin{array}{l}\text { CUKUP } \\
\text { PUAS }\end{array}$ \\
\hline $\begin{array}{l}\text { Cara menyampai kan } \\
\text { materi tutor dalam proses } \\
\text { mengajar }\end{array}$ & 0 & 0 & 17 & 68 & 47 & 141 & 16 & 32 & 20 & 20 & 261 & 52,2 & $\begin{array}{l}\text { CUKUP } \\
\text { PUAS }\end{array}$ \\
\hline $\begin{array}{l}\text { Kepekaan tutor menerima } \\
\text { keluhan siswa pada yang } \\
\text { tidak paham materi }\end{array}$ & 0 & 0 & 2 & 8 & 37 & 111 & 49 & 98 & 12 & 12 & 229 & 45,8 & $\begin{array}{l}\text { CUKUP } \\
\text { PUAS }\end{array}$ \\
\hline $\begin{array}{l}\text { Komunikasi tutor pada } \\
\text { siswa saat proses } \\
\text { mengajar }\end{array}$ & 0 & 0 & 6 & 24 & 62 & 186 & 28 & 56 & 4 & 4 & 270 & 54 & $\begin{array}{l}\text { CUKUP } \\
\text { PUAS }\end{array}$ \\
\hline $\begin{array}{l}\text { Perhatian tutor kepada } \\
\text { siswa ketika siswa } \\
\text { bermasalah }\end{array}$ & 0 & 0 & 6 & 24 & 37 & 111 & 48 & 96 & 9 & 9 & 240 & 48 & $\begin{array}{l}\text { CUKUP } \\
\text { PUAS }\end{array}$ \\
\hline
\end{tabular}


Sumber: diolah peneliti

Berdasrakan hasil analisis menunjukkan 52 orang atau $57,2 \%$ menyatakan cukup puas mengenai pernyataan "Sikap tutor dalam menyampaikan salam pada siswa". Sebanyak 47 orang atau $52,2 \%$ cukup puas mengenai pernyataan "Cara menyampaikan materi tutor dalam proses mengajar". Sebanyak 37 orang atau $45,8 \%$ mersa cukup puas mengenai pernyataan "Kepekaan tutor menerima keluhan siswa pada yang tidak paham materi". Sebanyak 62 orang atau 54,0\% merasa cukup puas mengenai pernyataan "Komunikasi tutor pada siswa saat proses mengajar". Dan sebanyak 37 orang atau 48,0\% merasa cukup puas mengenai pernyataan "Perhatian tutor kepada siswa ketika siswa bermasalah"

\section{Diskusi}

Kualitas Pelayanan Lembaga Kursus Komputer Pada Pondok Pesantren Darul Hijrah Putra Martapura Selama ini.

Tabel 8: Distribusi Frekuensi Dimensi Kualitas Pelayanan 


\begin{tabular}{|c|c|c|c|c|c|}
\hline No & & DIMENSI JASA & $\begin{array}{c}\text { Perhitungan } \\
\text { Indeks \% }\end{array}$ & HASIL & Penilaian \\
\hline \multirow{5}{*}{1} & \multirow{4}{*}{$\begin{array}{c}\text { BUKTI } \\
\text { LANGSUNG }\end{array}$} & Kerapian dan kebersihan berpakaian & $324 / 500 \times 100$ & $64,80 \%$ & PUAS \\
\hline & & $\begin{array}{l}\text { Kebersihan ruang kelas secara } \\
\text { umum }\end{array}$ & $229 / 500 \times 100$ & $45,80 \%$ & CUKUP PUAS \\
\hline & & $\begin{array}{l}\text { Kenyamanan ruang lingkup dan } \\
\text { fasilitas saat digunakan }\end{array}$ & $211 / 500 \times 100$ & $42,20 \%$ & CUKUP PUAS \\
\hline & & $\begin{array}{l}\text { Kualitas Komputer saat digunakan } \\
\text { sebagai media belajar }\end{array}$ & $298 / 500 \times 100$ & $59,60 \%$ & CUKUP PUAS \\
\hline & & Total keseluruhan & $1062 / 2000 \times 100$ & $53,10 \%$ & CUKUP PUAS \\
\hline \multirow{4}{*}{2} & \multirow{3}{*}{ Kehandalan } & Pemberian nilai sesuai kriteria & $278 / 500 \times 100$ & $55,60 \%$ & CUKUP PUAS \\
\hline & & $\begin{array}{l}\text { Pemberian sertifikasi legalitas } \\
\text { pengajar }\end{array}$ & $213 / 500 \times 100$ & $42,60 \%$ & CUKUP PUAS \\
\hline & & $\begin{array}{l}\text { Kemudahan proses penyampaian } \\
\text { teori dan arahan tutor }\end{array}$ & $218 / 500 \times 100$ & $43,60 \%$ & CUKUP PUAS \\
\hline & & Total keseluruhan & $709 / 1500 \times 100$ & $47,20 \%$ & CUKUP PUAS \\
\hline \multirow{5}{*}{3} & \multirow{4}{*}{ Daya tanggap } & $\begin{array}{l}\text { Kesigapan tutor dalam memperbaiki } \\
\text { jika peralatan rusak }\end{array}$ & $231 / 500 \times 100$ & $46,20 \%$ & CUKUP PUAS \\
\hline & & $\begin{array}{l}\text { Kesigapan dan tanggapan menangani } \\
\text { keluhan siswa }\end{array}$ & $213 / 500 \times 100$ & $42,60 \%$ & CUKUP PUAS \\
\hline & & $\begin{array}{l}\text { Kesigapan dalam melayani } \\
\text { administrasi dan nilai yang } \\
\text { bermasalah }\end{array}$ & $253 / 500 \times 100$ & $50,60 \%$ & CUKUP PUAS \\
\hline & & $\begin{array}{l}\text { Kesiapaan tutor dalam mengawali } \\
\text { proses belajar }\end{array}$ & $267 / 500 \times 100$ & $53,40 \%$ & CUKUP PUAS \\
\hline & & Total keseluruhan & $964 / 2000 \times 100$ & $48,20 \%$ & CUKUP PUAS \\
\hline \multirow{5}{*}{4} & \multirow{4}{*}{ Jaminan } & $\begin{array}{l}\text { Keramahan tutor dalam } \\
\text { menyampaikan pelajaran }\end{array}$ & $147 / 500 \times 100$ & $29,40 \%$ & TIDAK PUAS \\
\hline & & $\begin{array}{l}\text { Kejujuran tutor dalam mengajarkan } \\
\text { yang harus diajarkan }\end{array}$ & $243 / 500 \times 100$ & $48,60 \%$ & CUKUP PUAS \\
\hline & & $\begin{array}{l}\text { Keterampilan tutor dalam } \\
\text { menyampaikan materi pelajaran }\end{array}$ & $168 / 500 \times 100$ & $33,60 \%$ & TIDAK PUAS \\
\hline & & $\begin{array}{l}\text { Ketrampilan teknisi dalam } \\
\text { memperbaiki gangguan teknis }\end{array}$ & $275 / 500 \times 100$ & $55,00 \%$ & CUKUP PUAS \\
\hline & & Total keseluruhan & $833 / / 2000 \times 100$ & $41,65 \%$ & CUKUP PUAS \\
\hline \multirow{6}{*}{5} & \multirow{5}{*}{ Empaty } & $\begin{array}{l}\text { Sikap tutor dalam menyampaikan } \\
\text { salam pada siswa }\end{array}$ & $286 / 500 \times 100$ & $57,20 \%$ & CUKUP PUAS \\
\hline & & $\begin{array}{l}\text { Cara menyampaikan materi tutor } \\
\text { dalam proses mengajar }\end{array}$ & $261 / 500 \times 100$ & $52,20 \%$ & CUKUP PUAS \\
\hline & & $\begin{array}{l}\text { Kepekaan tutor untuk menerima } \\
\text { keluhan siswa pada yang tidak paham }\end{array}$ & $229 / 500 \times 100$ & $45,80 \%$ & CUKUP PUAS \\
\hline & & $\begin{array}{l}\text { Komunikasi tutor pada siswa saat } \\
\text { proses mengajar }\end{array}$ & $270 / 500 \times 100$ & $54,00 \%$ & CUKUP PUAS \\
\hline & & $\begin{array}{l}\text { Perhatian tutor kepada siswa ketika } \\
\text { siswa bermasalah }\end{array}$ & $240 / 500 \times 100$ & $48,00 \%$ & CUKUP PUAS \\
\hline & & Total keseluruhan & $1286 / 2500 \times 100$ & $51,44 \%$ & CUKUP PUAS \\
\hline
\end{tabular}

\section{Sumber: data diolah peneliti}

1. Bukti Langsung / Tangible

Berdasarkan perhitungan Indeks secara keseluruhann di dapat hasil sebesar $53,10 \%$, yang artinya siswa merasa cukup puas dengan variabel bukti langsung, dikarenakan masih memiliki kekurangan ruang kelas yang masih berukuran kecil sedangkan jumlah siswa yang cukup banyak sehingga jadwal kegiatan bergantian membuat kenyamanan siswa menjadi merasa kurang 
memuaskan. Fasilitas seperti kipas angin dan AC masih belum maksimal. Fasilitas lain seperti komputer dan laptop sebagai media belajar harus segera di tambah sesuai dengan jumlah siswa yang mengikuti kursus, serta kebersihan ruang kelas masih terlihat belum bersih.

2. Kehandalan / Reliability

Berdasarkan perhitungan Indeks secara keseluruhan diperoleh hasil sebesar $47,2 \%$ yang artinya siswa masih merasa cukup puas dalam variabel kehandalan. Hal ini disebabkan karena pemberian nilai belajar pada siswa masih tidak sesuai kriteria pada masing-masing siswa. Hal tersebut berdampak kerugian pada siswa. Pemberian sertifikat tidak sesuai dengan waktu yang ditentukan, serta proses pembelajaran belum sepenuh nya dapat dipahami oleh siswa. Hal tersebut membuat siswa kurang semangat dalam mengikuti pelajaran tersebut.

3. Daya Tanggap / Responsiveness

Berdasarkan perhitungan Indeks secara keseluruhan diperoleh hasil sebesar $48,2 \%$ yang artinya siswa masih merasa cukup puas dalam variabel daya tanggap. Hal ini disebabkan masih kurang sigap para tutor dalam menangani berbagai hal seperti memperbaiki peralatan yang rusak kadang membutuhkan jasa orang lain diluar LPK yang memakan waktu yang cukup lama, dalam proses pembelajaran kurang professional tentunya akan berpengaruh pada pada hasil yang akan dicapai.

4. Jaminan / assurance

Berdasarkan perhitungan Indeks secara keseluruhan didapati hasil sebesar $41,65 \%$ yang artinya siswa masih merasa cukup puas dalam variabel Jaminan. Menurut sejumlah siswa cara tutor dalam penyampaian materi masih tidak memuaskan para siswa, karena tutor tidak menguasai materi yang disampaikan

5. Empati / Empathy

Berdasarkan perhitungan Indeks secara keseluruhan didapati hasil sebesar $51,44 \%$ yang artinya siswa masih merasa cukup puas dalam variabel Empati. Karena sebagian sikap tutor kurang memuaskan pada saat memulai pelajaran sehingga membuat komunikasi tidak lancar berakibat suasana kelas menjadi tegang sehingga siswa pun segan dan enggan untuk bertanya ataupun berbicara mengenai kurang pahamnya atau ungkapan lain tentang pelajaran kusus komputer tersebut.

Kualitas Pelayanan Lembaga Kursus Komputer untuk Meningkatkan Kepuasan Siswa Pondok Pesantren Darul Hijrah Putra Martapura yang seharusnya.

1. Bukti Fisisk / Tangible

LPK AL-Hijrah Putra pada Pondok Pesantren Darul Hijrah Putra Martapura agar secepatnya membenahi ruang kelas dengan Merenovasi bangunan dengan menambah ruang kelas yang lebih besar supaya dapat menampung siswa yang kursus sehingga tidak mengganggu proses belajar. Fasilitas lain yang mendukung proses pembelajaran seperti kipas angin, AC, meja, kursi dan peralatan keperluan lain supaya bisa di lengkapi setiap ruangan agar terlaksana dengan baik dan lancar. 
2. Kehandalan / Reliability

LPK AL-Hijrah Putra harus subjektif memberikan nilai dengan menyesuaikan standar ketetapan yang berlaku sehingga tidak ada siswa yang merasa dirugikan. Jika semua siswa disama ratakan akan terjadi ketidaksesuaian penilaian yang menyebabkan ketidak puasan bagi siswa yang kreatif dan disiplin. Penyerahan sertifikat sesuai dengan waktu yang ditentukan, sehingga dapat digunakan dan lebih bermanfaat untuk siswa. Dalam penyampaian materi harus sesuai dengan buku pedoman yang ada, penguasaan materi menjadi siswa focus dan semangat dalam mendengarkan dan memahami materi yang disampaikan.

3. Daya Tanggap / Responsiveness

LPK AL-Hijrah pada Pondok Pesantren Darul Hijrah Putra Martapura agar lebih sigap dalam mengatasi segala kemungkinan yang terjadi seperti memperbaiki peralatan yang rusak, sehingga tidak mengganggu proses belajar dan dapat berjalan sesuai dengan waktu yang tersedia tanpa hambatan dan gangguan kerusakan walau itu hanya sekecil Virussoftware. Setiap selesai proses belajar hendaknya tetap terus lakukan evaluasi terhadap seluruh aspek proses belajar LPK Al-Hijrah agar tujuan yang hendak dicapai sesuai sasaran.

4. Jaminan / assurance

LPK AL-Hijrah Putra pada Pondok Pesantren Darul Hijrah Putra Martapura supaya membuat metode pembelajaran yang baru tidak membosankan, sehingga siswa yang masih duduk di SMP kelas 1 bisa menerima proses belajar yang diberikan oleh tutor. Ketegasan yang diberikan akan berdampak baik walau ternyata tak semua ketegasan yang diberikan akan dapat diterima oleh semua siswa yang mengikuti kursus tersebut. Disamping itu tutor harus mampu mengantisipasi kendala ataupun kerusakan teknisi agar dapat terselesaikan dengan cepat dan tidak mengganggu waktu proses belajar supaya berjalan dengan waktu yang telah ditentukan oleh pondok pesantren darul hijrah putra martapura.

5. Empati / Empathy

LPK AL-Hijrah Putra pada Pondok Pesantren Darul Hijrah Putra Martapura sebaiknya dalam berkomunikasi kepada siswa harus memperhatikan etika yang berlaku selama proses mengajar. Lebih peka dan perhatian kepada setiap sikap individu siswa supaya tutor bisa lebih mudah menilai karakter dan menyesuaikan dengan standar ketentuan yang berlaku. Komunikasi yang baik akan memudahkan siswa menerima setiap peratuan pada LPK AL-Hijrah Putra ini. Hal tersebut dilakukan untuk keberlangsungan proses mengajar karena kedua belah pihak antara tutor maupun siswa telah terjalin komunikasi yang baik. 


\section{Kesimpulan dan Keterbatasan Penelitian}

Dari pembahasan yang telah dilakukan terhadap hasil penelitian ini, dapat ditarik kesimpulan sebagai berikut:

1. Kepuasan siswa di LPK AL-Hijrah dilihat dari variabel Tangible (bukti fisik), Reliability (kehandalan), Responsiveness (daya tanggap), Assurance (jaminan), Empathy (empati) sebanyak 100 responden dihitung berdasarkan teknik skala likert dengan Nilai Rata - rata sebesar 48,31\% menyatakan masih merasa cukup puas

2. Kualitas pelayanan yang seharusnya diterapkan untuk meningkatkan kepuasan siswa pada LPK AL-Hijrah pada Pondok Pesantren Darul Hijrah Putra Martapura dengan melakukan perbaikan dan pembenahan pada semua variabel Tangible (bukti fisik), Reliability (kehandalan), Responsiveness (daya tanggap), Assurance (jaminan), Empathy (empati) sehingga kedepannya siswa merasa puas.

\section{DAFTAR PUSTAKA}

Abbas Salim. (2007). Asuransi dan Manajemen Resiko. Jakarta: Raja Grasindo Persada.

Abdullah, Thamrin, Francis Tantri, 2014, Manajemen Pemasaran, RajaGrafindo Persada, Jakarta.

Abidin, Yunus. (2014). Desain Sistem Pembelajaran Dalam Konteks Kurikulum 2013. Bandung: PT Refika Aditama

Anggraini, Luciana, 2012, Analisis Strategi Pemasaran Produk Tahu Di Rumah Makan Aneka Tahu Maju Lestari, STIE Pancasetia, Banjarmasin.

Aprizal, 2013, Analisis Daya Saing Usaha Tani Kelapa Sawit Kabupaten Mukomuko, Universitas Bengkulu, Bengkulu.

Arikunto, S. (2013). Prosedur Penelitian: Suatu Pendekatan Praktik. Jakarta: Rineka Cipta.

Assauri, Sofjan, 2014, Manajemen Pemasaran Dasar Konsep dan Strategi, RajaGrafindo Persada, Jakarta.

Faiq Abdul A. Kualitas Pelayanan Pendidikan Lembaga Kursus dan Pelatihan (LKP) Dian Gitaya. http//:Skripsi/Penelitian/terdahulu/FAIQABDULAZIZ 1351122 html (Diakses pada bulan April 2017).

Fandy Tjiptono, (2011). Manajemen \& Strategi Merek, Penerbit Andi, Yogyakarta Handoko, T. H. (2015). Manajemen Edisi 2. Yogyakarta: BPFE

J. Supranto (2016). Statistik : Teori dan Aplikas Jilid 2 Edisi 8. Jakarta : Erlangga.

Kotler, Keller, Philip. (2011). Manajemen Pemasaran. Edisi tiga belas Bahasa Indonesia.Jilid 1 dan 2.Jakarta : Erlangga.

Moenir, (2012). Manajemen Pelayanan Umum di Indonesia. Jakarta: Bumu Aksara.

Nazir. M (2009). Metode Penelitian. Bogor : Ghalia Indonesia.

Potter, Perry. (2010). Fundamental Of Nursing: Consep, Proses and Practice.

Edisi 7. Vol. 3. Jakarta : EGC

Samosir, Z. Z. (2005) Pengaruh kualitas Pelayanan Terhadap Kepuasan Mahasiswa Menggunakan Perpustakan USU. Jurnal Studi Perpustakaan Dan Informasi, [internet] 1(1). 28 36, Available. 
Sugiyono (2014). Metode Penelitian Bisnis. Bandung: Alfabeta.

Thoha, (2013). Manajemen Pelayanan di Indonesia. Jakarta: Kencana.

Tjiptono, Fandy, (2000). Manajemen Jasa, Edisi Kedua, Andy Offset. Jakarta

Triatmojo, Pohan (2010) Studi Pengaruh Kualitas untuk Meningkatkan Kepuasan. thesis, Perpustakaan UGM. Yogyakarta.

Usmara. (2011). Pengujian hubungan kualitas jasa, kepuasan nasabah dan intensi pembelian ulang. UNSPECIFIED thesis. Bank BRI. Yogyakarta. 